\title{
Regeneration of nitrate and phosphate from toilet wastewater using waste alumina adsorbent for cultivation of Spirulina platensis
}

\author{
Sang-Jun Lee ${ }^{1,2^{*}}$, Seonghwan Park ${ }^{1,2^{*}}$, Won Noh $^{1,2}$, Dong-Hyuk Yeom ${ }^{2}$, Sooyeon Kim ${ }^{2}$, \\ Dae-wook Kim ${ }^{2}$, Jungmin Kim $^{1,3^{+}}$ \\ ${ }^{1}$ Biomass Research Group, Gyeongnam Department of Environmental Toxicology \& Chemistry, Korea Institute of Toxicology, Jinju-si, 52834, Republic \\ of Korea \\ ${ }^{2}$ Eco-Toxicology Research Group, Gyeongnam Department of Environmental Toxicology \& Chemistry, Korea Institute of Toxicology, Jinju-si 52834, \\ Republic of Korea \\ ${ }^{3}$ Environmental Biology Research Group, Gyeongnam Department of Environmental Toxicology \& Chemistry, Korea Institute of Toxicology, Jinju-si, \\ 52834, Republic of Korea \\ "These authors contributed equally to this work
}

\section{ABSTRACT}

The use of different types of wastewater (WW) for the cultivation of microalgae and cyanobacteria during recent decades has provided important economic and environmental benefits. However, direct use of WW can lead to growth inhibition and biomass contamination. In the present study, we separated the key WW nutrients, namely nitrate and phosphate, by adsorption and regeneration and used the resulting regenerated water to cultivate the cyanobacterium Spirulina platensis. The adsorbent was granular $\gamma$-alumina derived from waste aluminum cans. This procedure recovered $19.9 \%$ of nitrate and $23.7 \%$ of phosphate from WW. The cyanobacterial cultures efficiently assimilated the nutrients from the medium prepared using regenerated WW, and the growth and nutrient uptake were similar to those in a synthetic medium. In addition, imposing nutrient limitations to increase carbohydrate productivity was easily achieved using regenerated wastewater nutrients, without requiring additional dilution or complex processing. In acute toxicity tests, the harvested biomass in a regenerated medium had similar toxicity levels compared to the biomass obtained from a synthetic medium. The proposed method of using regenerated WW to produce contamination-free biomass has broad potential applications.

Keywords: Nutrient recovery, Regenerated medium, Spirulina platensis, Toilet wastewater, Toxicity test

\section{Introduction}

Previous research indicates that utilization of wastewater (WW) for production of microalgal and cyanobacterial biomass can reduce the costs and energy required for purifying water and nutrient recovery and can also improve the quality of discharged water [1]. Most studies have applied WW directly for microalgae cultivation as a liquid broth and nutrient source. Ruiz-Marin et al. [2] reported the elimination of $\mathrm{NH}_{4}-\mathrm{N}(100 \%)$ and $\mathrm{PO}_{4}-\mathrm{P}(83 \%)$ in urban WW treated using Scenedesmus obliquus. Green alga, Chlorella vulgaris, can consume $86 \%$ of inorganic N and $78 \%$ of inorganic $\mathrm{P}$ contained in primary settled WW [3].

However, WW contains toxic compounds as well as important nutrients. Industrial WW includes heavy metals and organic substances as major pollutants; the compositions and concentrations are complex and vary depending on the WW source [4]. Agricultural WW mainly contains organic phosphorus and pesticides that have strong toxicity $[4,5]$. Human pharmaceuticals and metabolites were persisted in toilet WW, which can accumulate in most organisms owing to its hydrophobic and persistent nature [6]. Therefore, direct use of WW may inhibit microalgal growth and contaminate the resulting biomass [7]. Additional treatments of WW, such as dilution with other water sources or cultivation of other microbes, may be needed before inoculation of microalgal cultures into WW streams [8].

Recent research proposed transformation of conventional WW into toxic and nontoxic portions using an indirect approach $[9,10]$.
This is an Open Access article distributed under the terms of the Creative Commons Attribution Non-Commercial License (http://creativecommons.org/licenses/by-nc/3.0/) which permits unrestricted non-commercial use, distribution, and reproduction in any medium, provided the original work is properly cited.
Received November 18, 2018 Accepted May 25, 2019

${ }^{\dagger}$ Corresponding author

Email: jungmin.kim@kitox.re.kr

Tel: +82-55-750-3766 Fax: +82-55-750-3799 
Unlike conventional WW processing, in which the entire WW is used, the indirect approach employs the useful portion of WW for microalgae cultivation. Therefore, a key step in the production of useful WW portions is the efficient and safe separation of useful nutrients, especially nitrogen and phosphorous, from the original WW. The recovered WW nutrients can be used for biomass production without the problems of toxicity and contamination. Therefore, the proposed method of using regenerated WW to produce contamination-free biomass has broad potential applications.

Hence, the objective of this study was to investigate the applicability of WW nutrients recovered using a granular $\gamma$-alumina adsorbent for the cultivation of Spirulina platensis. The regenerated water (RW) was obtained by desorption of nitrate and phosphate from the adsorbent and used for cyanobacterial cultivation. The growth rate, quantum yield, and nutrient assimilation were measured and the effect of nutrient limitation on growth and biomass composition in an effort to further improve the indirect WW process was also evaluated. Furthermore, to evaluate the quality of the harvested biomass, acute toxicity test was evaluated through a standardized $48 \mathrm{~h}$ immobilization test using Daphnia magna.

\section{Materials and Methods}

\subsection{Preparation of Granular Mesoporous $\gamma$-alumina for Nitrate and Phosphate Recovery}

Waste aluminum cans were cut into small pieces and added to a $1 \mathrm{M}$ hydrochloric acid solution to produce an aluminum chloride solution. Organic impurities were then removed by calcination at $300^{\circ} \mathrm{C}$ in an electric furnace (AJ-MBOT1, AH Jeon Industrial Co., Republic of Korea). After separation of unreacted solids, aluminum chloride was gelated by titration with concentrated sodium hydroxide. The resulting solution was converted to granular-type boehmite $(\mathrm{AlOOH})$ using the oil-drop granulation method [11]. After calcination of granular boehmite at $400^{\circ} \mathrm{C}$, granular mesoporous $\gamma$-alumina was obtained for use as an adsorbent to recover nitrate and phosphate from WW.

\subsection{Preparation of RW with Nitrate and Phosphate}

The WW source was the septic tank of a public restroom in Yeongnak Park, Gwangju, Republic of Korea. To produce RW, 200 g/L of the adsorbent was added to $15 \mathrm{~L}$ of WW (Fig. S1). After stirring for $12 \mathrm{~h}$, the adsorbent was separated by gravitational settling and then resuspended in $2 \mathrm{~L}$ of deionized water. To desorb the nitrate and phosphate, a small volume of $1 \mathrm{M} \mathrm{NaOH}$ was added until the $\mathrm{pH}$ reached 12.0. After overnight stirring, RW (an aqueous solution of nitrate and phosphate) was obtained. Table 1 presents the physicochemical properties of WW and RW.

\subsection{Cultivation of Spirulina Platensis with Regenerated WW Nutrients}

Spirulina platensis (PS-0056) was kindly provided by the Library for Marine Samples (LIMS) (Fig. S2). All inocula were cultivated in a Zarrouk medium [12]. The regenerated medium (RM) and diluted $\mathrm{RM}(1 / 2 \times \mathrm{RM})$ were synthesized using RW as the source
Table 1. Composition of Original Wastewater (WW), Wastewater after Adsorption, and Regenerated Water (RW).

\begin{tabular}{lccc}
\hline Component & $\begin{array}{c}\text { Original WW, WW after adsorption, } \\
\text { ppm }\end{array}$ & $\begin{array}{c}\text { RW, } \\
\text { ppm }\end{array}$ \\
\hline $\mathrm{COD}_{\mathrm{Cr}}$ & 244.2 & 185.9 & 2.1 \\
$\mathrm{TN}$ & 152.0 & 9.8 & 213.9 \\
$\mathrm{NH}_{3}-\mathrm{N}$ & 8.3 & 0.3 & 0.1 \\
$\mathrm{NO}_{2}-\mathrm{N}$ & $\mathrm{N} . \mathrm{D}$. & $\mathrm{N} . \mathrm{D}$. & N.D. \\
$\mathrm{NO}_{3}-\mathrm{N}$ & 143.1 & 4.1 & 213.5 \\
$\mathrm{PO}_{4}-\mathrm{P}$ & 22.9 & 1.1 & 40.7 \\
$\mathrm{SS}$ & 16.5 & 8.9 & 0.2 \\
$\mathrm{DO}$ & 4.6 & 4.8 & 4.4 \\
$\mathrm{pH}$ & 8.04 & 7.6 & 7.8 \\
$\mathrm{Turbidity,} \mathrm{NTU}$ & 14.0 & 4.1 & 0.6 \\
$\mathrm{~Pb}$ & 0.003 & 0.002 & N.D. \\
$\mathrm{Zn}$ & 0.012 & 0.013 & N.D. \\
$\mathrm{Fe}$ & 0.129 & 0.128 & N.D. \\
\hline $\mathrm{Abb}$ & & &
\end{tabular}

Abbreviations: COD, chemical oxygen demand based on dichromate analysis; DO, dissolved oxygen; N.D., not detected; NTU, nephelometric turbidity units; SS, suspended solids; TN, total nitrogen.

of nitrate and phosphate. The nitrate and phosphate levels of the $1 / 2 \times \mathrm{RM}$ were half of those in the original RW. With the exception of nitrate and phosphate, the concentrations of all other nutrients were identical to those in the control medium (CM). The modified Zarrouk medium (used as the CM) included nitrate and phosphate concentrations identical to those of the RM, with adjustments performed using commercial reagents. Growth in WW and filtered WW by using $0.45-\mu \mathrm{m}$ pore-size vacuum filter ( $500 \mathrm{~mL}$ bottle top vacuum filter, Corning, USA) (fWW) was compared to growth in $\mathrm{RM}, 1 / 2 \times \mathrm{RM}$, and CM. Table 2 presents the initial nutrient composition of CM, RM, $1 / 2 \times \mathrm{RM}$, WW, and fWW. All experiments were conducted in duplicate in $500 \mathrm{~mL}$ baffled flasks containing $400 \mathrm{~mL}$ of cyanobacterial culture with stirring in a shaking incubator (HB-201MS-4R, Hanbaek Co., Republic of Korea) at $20^{\circ} \mathrm{C}$ under $100 \mu \mathrm{mol} / \mathrm{m}^{2} \cdot \mathrm{s}$ of continuous irradiation using cool white fluorescent tubes (PL-L, 36W, Philips, Korea) (Fig. S2).

\subsection{Acute Immobilization Test with Microalgal Biomass}

Because microalgae can assimilate toxic substances, such as heavy metals and chemicals, persisted in WW [13], proper toxicity tests are needed to evaluate the quality of harvested biomass. To evaluate the toxic effect of microalgal biomass on daphnids, an acute immobilization test was performed in accordance to the OECD guideline 202: Daphnia sp., acute immobilization test [14]. Biomass samples harvested from the CM, RM, and $1 / 2 \times \mathrm{RM}$ as well as a negative control (M4 medium only) were used for the experiment. Five neonates of Daphina magna straus, 1820, aged less than $24 \mathrm{~h}$, were exposed to different biomass concentrations $(6.3,12.5,25,50$, and $100 \mathrm{mg} / \mathrm{L})$ for $48 \mathrm{~h}\left(20 \pm 1^{\circ} \mathrm{C}\right.$ and a 16:8 h light:dark photoperiod $)$, and each exposure concentration included four replicates (Fig. S4). After 
Table 2. Composition of Control Medium (CM), Regenerated Medium (RM and $1 / 2 \times R M)$, Wastewater (WW), and Filtered WW (fWW) Used for Cultivation of Spirulina Platensis

\begin{tabular}{lcccc}
\hline Component & $\mathbf{C M}(\mathbf{g} / \mathbf{L})$ & $\mathbf{R M}(\mathbf{g} / \mathbf{L})$ & $1 / 2 \times \mathbf{R M}(\mathbf{g} / \mathbf{L})$ & $\mathbf{W W}$ and fWW $(\mathbf{g} / \mathbf{L})$ \\
\hline $\mathrm{NaHCO}_{3}$ & 16.8 & 16.8 & 16.8 & - \\
$\mathrm{N}$ source & $1.290\left(\mathrm{NaNO}_{3}\right)$ & $0.942\left(\mathrm{NO}_{3}\right)$ & $0.474\left(\mathrm{NO}_{3}\right)$ & $0.779\left(\mathrm{NO}_{3}\right)$ \\
$\mathrm{P}$ source & $0.229\left(\mathrm{~K}_{2} \mathrm{HPO}_{4}\right)$ & $0.126\left(\mathrm{PO}_{4}\right)$ & $0.061\left(\mathrm{PO}_{4}\right)$ & $0.049\left(\mathrm{PO}_{4}\right)$ \\
$\mathrm{K} 2 \mathrm{SO} 4$ & 1 & 1 & 1 & - \\
$\mathrm{NaCl}$ & 1 & 1 & 1 & - \\
$\mathrm{CaCl}_{2} \cdot 2 \mathrm{H}_{2} \mathrm{O}$ & 0.04 & 0.04 & 0.04 & - \\
$\mathrm{Na}_{2} \mathrm{EDTA}_{2} \mathrm{H} \mathrm{H}_{2} \mathrm{O}$ & 0.08 & 0.08 & 0.08 & - \\
$\mathrm{MgSO}_{4} \cdot 7 \mathrm{H}$ & $\mathrm{O}$ & 0.2 & 0.2 & - \\
$\mathrm{FeSO}_{4} \cdot 7 \mathrm{H}_{2} \mathrm{O}$ & 0.2 & 0.01 & 0.01 & - \\
$\mathrm{Trace} \mathrm{elements}$ & 0.01 & 1 & 1 & - \\
\hline
\end{tabular}

gentle agitation of the test vessel, the number of daphnids immobilized was recorded after 24 and $48 \mathrm{~h}$ of exposure. The dissolved oxygen (DO) and $\mathrm{pH}$ were measured at the beginning and end of the test.

\subsection{Analytical Methods}

The dry cell weight was measured indirectly using ultraviolet spectrophotometry (UV-1800, Shimadzu, Japan) at $660 \mathrm{~nm}$. Nitrate and phosphate assimilations by Spirulina platensis were determined using ion chromatography (930 compact IC, Metrohm AG, Switzerland). The maximum quantum yield of photosystem II $\left(F_{v} / F_{m}\right)$ was measured as a function of cultivation time after dark adaptation to achieve equilibrium in photosystem II (Aquapen C-100, PSI, Czech Republic). Quantum yield is a reliable indicator of the photosynthetic efficiency of cyanobacterial cultures [15]. After cultivation, cyanobacterial biomass was collected through centrifugation at 5,000 rpm for $10 \mathrm{~min}$, followed by lyophilization and storage at $-20^{\circ} \mathrm{C}$ for analysis of cellular composition. Carbohydrate concentration was determined using the phenolsulfuric acid method, with dextrose as a standard [16]. Protein concentration was determined by multiplying the nitrogen content determined using an elemental analyzer by 4.78 (Flash 2000, Thermo Fisher Scientific, USA) [17]. Lipid concentration was determined using the sulfo-phospho-vanillin method, with soybean oil as a standard [18].

\section{Results and Discussion}

\subsection{Recovery of WW Nutrients and Preparation of RW}

After adsorption and desorption of WW, we recovered $19.9 \%$ of the nitrate and $23.7 \%$ of the phosphate contained in the WW (Table 1). Although adsorption removed $97.1 \%$ of the nitrate and $95.2 \%$ of the phosphate from the original WW, increasing the $\mathrm{pH}$ to 12.0 led to a low desorption capacity and poor regeneration of these nutrients. In particular, the granular $\gamma$-alumina adsorbent only desorbed $20.5 \%$ of the nitrate and $24.9 \%$ of the phosphate. The adsorbent we used was designed to adsorb anions, such as fluoride, sulfate, phosphate, and nitrate, from water streams through electrostatic attachment onto the positively charged alumina surface. Adjusting the $\mathrm{pH}$ alters the surface charge of an adsorbent [19]. Thus, at high $\mathrm{pH}$ values, the adsorbent surface has a negative charge, and this hinders the adsorption of anions owing to columbic repulsion. However, adjusting the $\mathrm{pH}$ did not provide effective regeneration of adsorbed WW nutrients in this system. Use of another desorption method may improve the recyclability of nutrients from WW.

Microalgal and cyanobacterial cells assimilate nutrients and toxic compounds simultaneously from WW, so it is essential to separate the nutrients from the toxic compounds. Table 1 show that the chemical oxygen demand (COD), suspended solids (SS), turbidity, ammonia, and heavy metals are considerably reduced in RW. Thus, the granular $\gamma$-alumina adsorbent effectively removed compounds that could hinder biomass production.

\subsection{Cultivation of Spirulina Platensis Using RW}

We investigated the effect of the RM on cyanobacterial biomass productivity and composition by comparing the growth in the CM, $\mathrm{RM}, 1 / 2 \times \mathrm{RM}, \mathrm{WW}$, and fWW (Table 2). We prepared the RM using RW, adding the same nutrients used in the CM, except nitrate and phosphate. In addition, when preparing the CM, we adjusted the nitrate and phosphate concentrations to the same levels as in the RM.

WW and fWW did not support the growth of cyanobacteria, even though these had sufficient levels of nitrate and phosphate, possibly because of the presence of toxic substances (Fig. 1(a)). Thus, direct use of this WW is unsuitable for the growth of Spirulina platensis. However, cultivation of Spirulina platensis in the CM and RM led to similar growth responses (Fig. 1(a)). At the end of the cultivation $(209 \mathrm{~h})$, the dry cell weight was $1.61 \pm 0.05$ $\mathrm{g} / \mathrm{L}$ in the $\mathrm{CM}$ and $1.43 \pm 0.1 \mathrm{~g} / \mathrm{L}$ in the RM. Growth was also similar in $1 / 2 \times$ RM until $143 \mathrm{~h}$, after which growth nearly stopped owing to depletion of nitrate.

We also measured the quantum yield of photosynthesis in the cyanobacterial cultures to assess the effect of different media on 

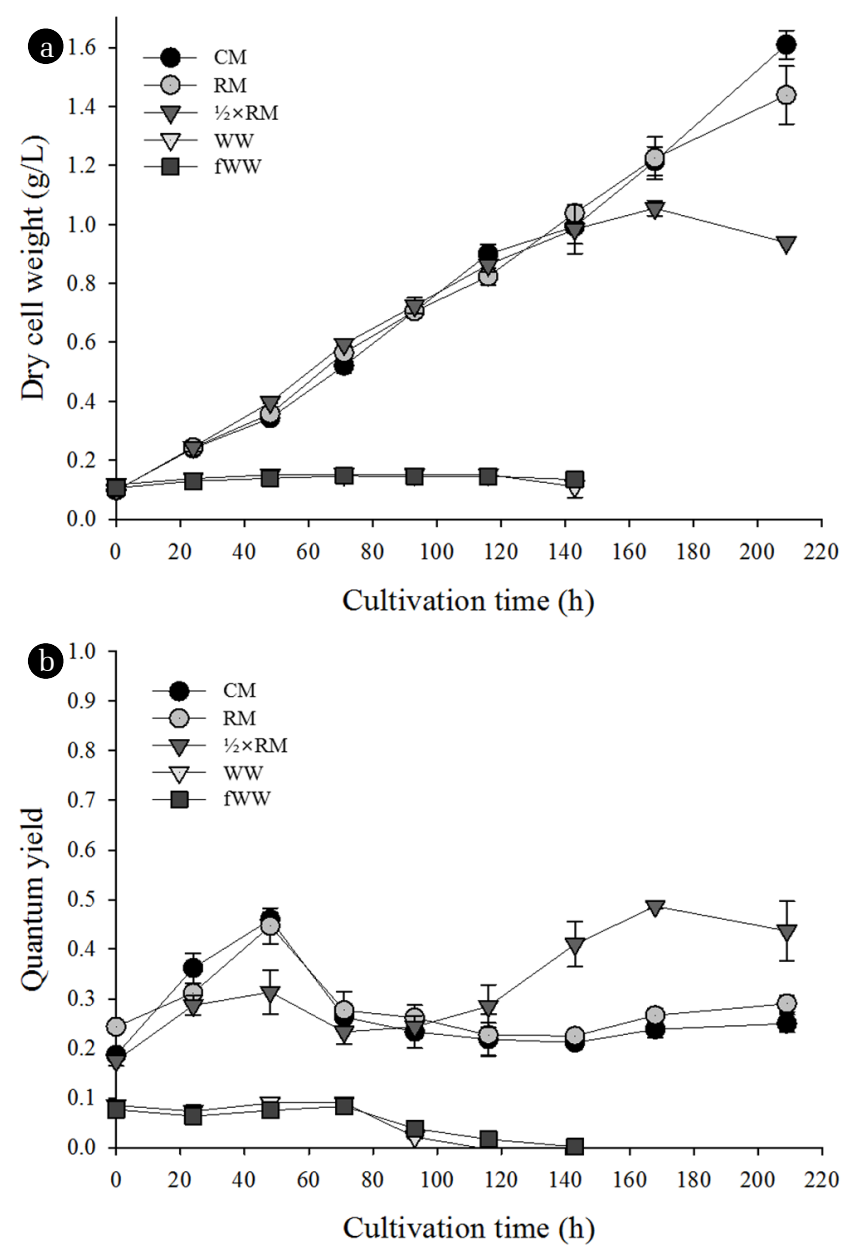

Fig. 1. Growth (a) and quantum yield (b) of S. Platensis cultivated in different media.

photosynthetic activity (Fig. 1(b)). The results show that the quantum yields of cultures in CM, RM, and $1 / 2 \times$ RM were above 0.25 . However, cultures in WW and fWW had gradually decreasing quantum yields that reached zero at $143 \mathrm{~h}$. This finding suggests that RM, which has nitrate and phosphate from WW, had no evident toxic effects on cyanobacterial cells. Cyanobacterial cultures grown in $\mathrm{CM}, 1 / 2 \times \mathrm{RM}$, and RM developed changes in color, from blue-green to dark green, during cultivation, whereas cultures in WW and fWW began to lose their blue-green color after $48 \mathrm{~h}$ (Fig. S3). In addition, the color of the culture changed faster in WW than fWW.

Fig. 2 shows the rates of nitrate and phosphate assimilation by Spirulina platensis in different media. The removal rates were nearly the same in CM and RM during the entire cultivation period. Nutrient removal from $1 / 2 \times \mathrm{RM}$ was also similar up to $120 \mathrm{~h}$, where there was nitrate depletion. After the depletion of nitrate from $1 / 2 \times R M$, phosphate assimilation also stopped, even though the supply was not limited. This can be explained by considering the roles of nitrogen and phosphorous in cellular metabolism [20]. Photosynthetic organisms, such as microalgae and cyanobacteria,
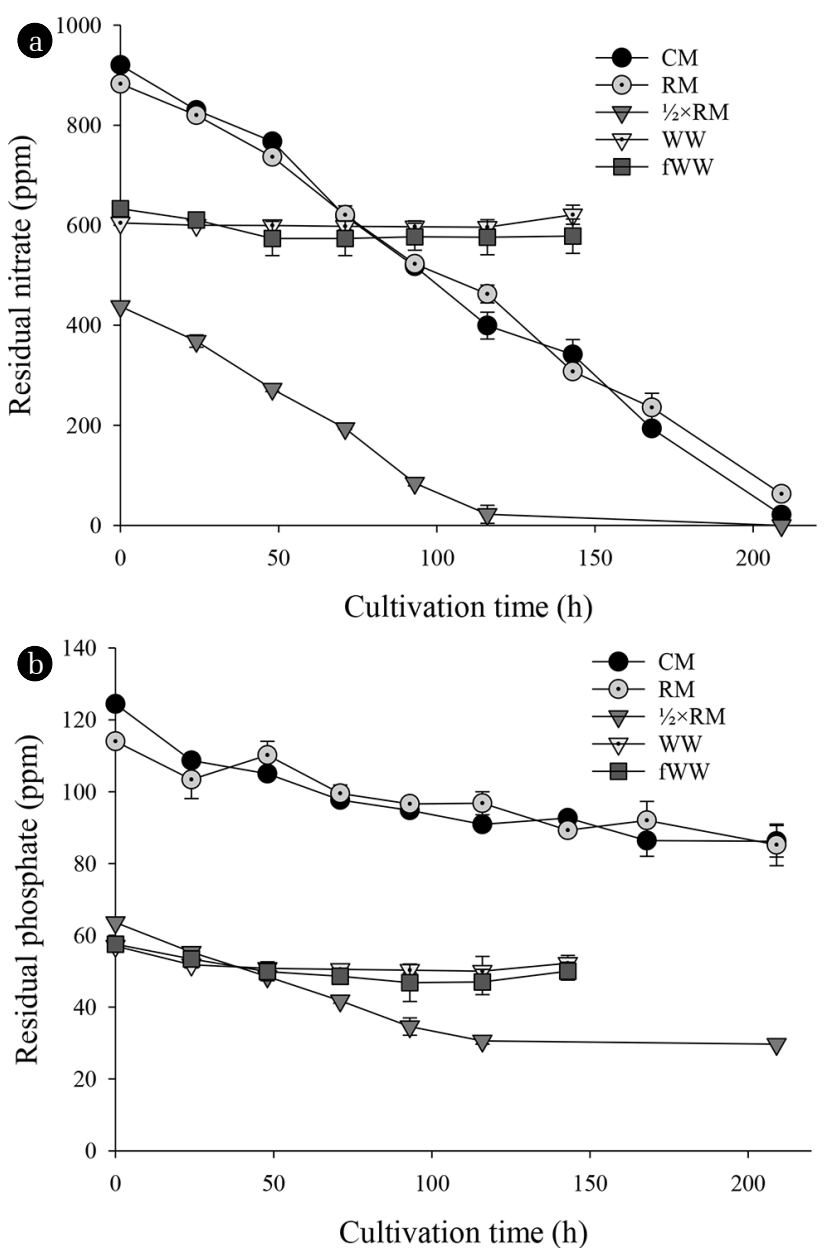

Fig. 2. Uptake of nitrate (a) and phosphate (b) by S. Platensis cultures in different media.

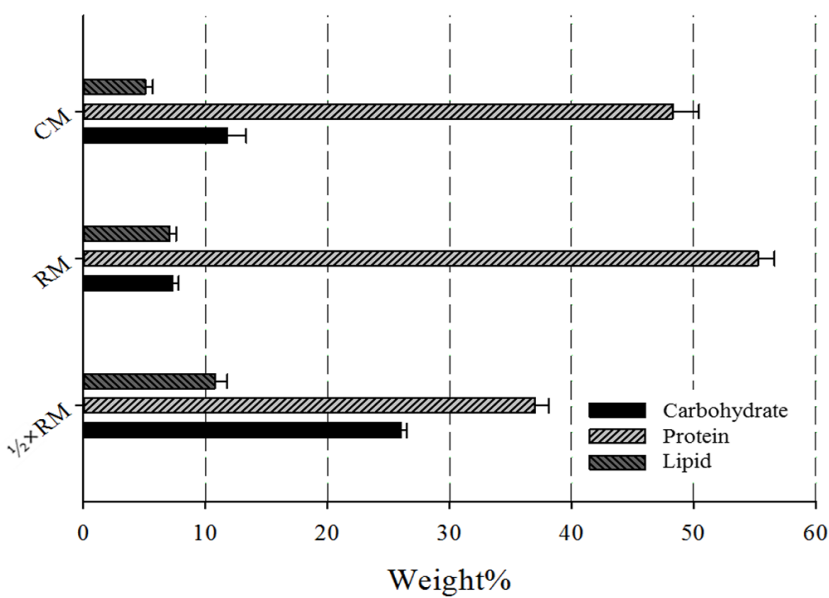

Fig. 3. Biomass composition of $S$. platensis grown in commercial and regenerated media.

mainly integrate nitrogen into proteins, so nitrogen depletion reduces protein synthesis and reduces the number and amount of ribosomal RNA. Cells store most of their phosphorous in ribosomal 
RNA, so the reduced number of ribosomes reduces the cellular phosphorous concentration.

Fig. 3 shows the cyanobacterial biomass composition following cultivation in CM, RM, and $1 / 2 \times \mathrm{RM}$. The protein content was 48.3\% for cultivation in CM and $55.3 \%$ for cultivation in RM, in accordance with the general protein content of healthy Spirulina cells ( $\sim 50 \%)$. The low protein content of $37 \%$ in $1 / 2 \times$ RM was due to nitrogen starvation. Because of nitrogen starvation, the carbohydrate content was 3.6 times greater and the lipid content was 1.5 times greater for cells grown in $1 / 2 \times \mathrm{RM}$.

Nitrogen starvation is one of the easiest ways to induce cell stress and alter the chemical composition of cells [21]. When using WW directly, nitrogen starvation can be achieved by dilution with copious amounts of other water sources or using a complex multistage cultivation system. In contrast, RW can be used like a commercial fertilizer, without the need for additional water or a complex cultivation system, to achieve high productivity of lipids or carbohydrates. We found that carbohydrate productivity (g/g of biomass) was 2.3 times higher when cells were grown in $1 / 2 \times$ $\mathrm{RM}$ compared to RM. There were also interesting differences in the biomass composition, especially carbohydrate and protein compositions, of cells grown in CM and RM. Even when there is no nitrogen limitation, the carbohydrate content was $60 \%$ higher and protein content was $14 \%$ lower when cells were cultivated in CM rather than RM. A previous paper [20] reported that phosphorous assimilation had a negative correlation with carbohydrate concentration in some species of microalgae. As noted above, nitrogen depletion reduces the assimilation of phosphorous. Thus, based on our observations regarding the composition of cyanobacterial biomass, regenerated nutrients are more likely to be assimilated and used in biochemical synthesis. A possible reason for this is the absence of cations, such as sodium and potassium, which bind to nitrate and phosphate, in the RM. Previous studies have reported the negative impact of metal cations on the bioavailability of nitrate and phosphate in microalgal and cyanobacterial cells [22,23].

\subsection{Acute Immobilization Test with Microalgal Biomass}

The results obtained from the acute immobilization test are presented in Table 3 and Fig. 4 . The $\mathrm{pH}$ was maintained to ensure neutral or weakly alkaline conditions during the $48 \mathrm{~h}$ exposure test (Fig. 4(c)) and low DO levels were observed at $100 \mathrm{mg} / \mathrm{L}$ in $\mathrm{CM}, 1 / 2 \times \mathrm{RM}$, and $\mathrm{RM}(3.83 \pm 0.54 \mathrm{mg} / \mathrm{L}, 5.03 \pm 0.41$, and $4.57 \pm 0.42 \mathrm{mg} / \mathrm{L}$, respectively) (Fig. 4(b)). Several studies reported that low DO concentrations can lead to both acute and chronic toxic effects on daphnids. Ferreira et al. [14] reported that the feeding rates of $D$. magna for a 28-h exposure decreased when the DO concentration was below $6 \mathrm{mg} / \mathrm{L}$. Nebeker et al. [25] reported the reduced survival and reproduction of Daphnia pulex in chronic tests at low DO concentrations $(2.2 \mathrm{mg} / \mathrm{L}$ ). However, some studies revealed that the DO concentration did not affect the mortality of daphnids. Borgeraas and Hessen [26] reported that oxygen concentration (5.6-14.1 mg/L) did not influence the survival of adult Daphnia magna during UV-B exposure tests. Adult Daphnia magna also shows a high degree of respiratory independence at declining oxygen concentrations and is able to maintain the oxygen consumption rate down to a critical
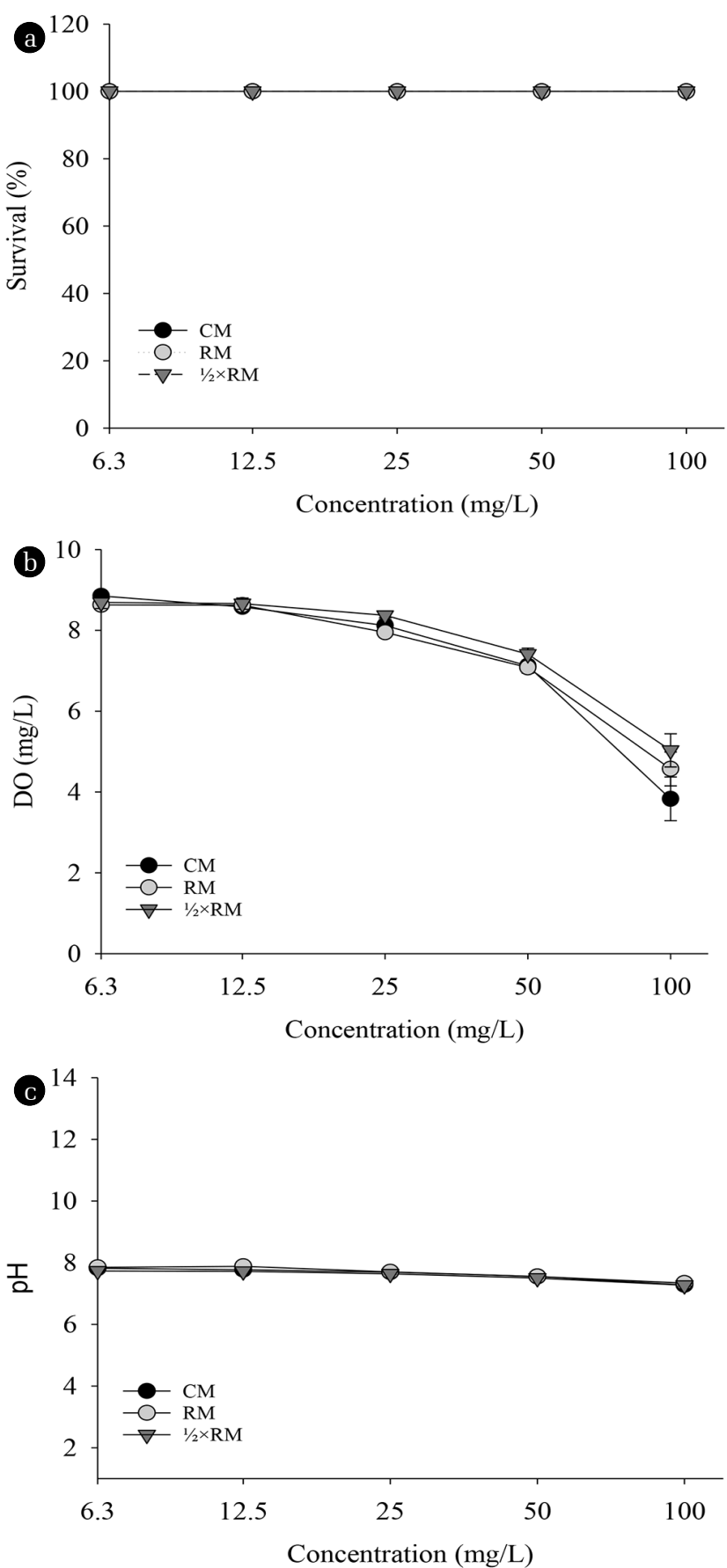

Fig. 4. Survival of D. magna (a), DO (b) and $\mathrm{pH}$ (c) values for $48 \mathrm{hr}$ acute immobilization test using various concentrations of $S$. Platensis cultures in different media.

concentration (1 mg/L) [27]. In the present study, no mortality was observed after $48 \mathrm{~h}$ following the experiment. It means that low DO levels did not affect to the mortality of daphnids in all conditions.

From the results, it was confirmed that Spirulina platensis cultures grown in the RM and $1 / 2 \times \mathrm{RM}$ had similar toxic effects 
Table 3. Results of the Daphnia Magna Acute immobilization Test with S. Platensis Grown in Control Medium (CM) and Regenerated Medium (RM and $1 / 2 \times R M)$.

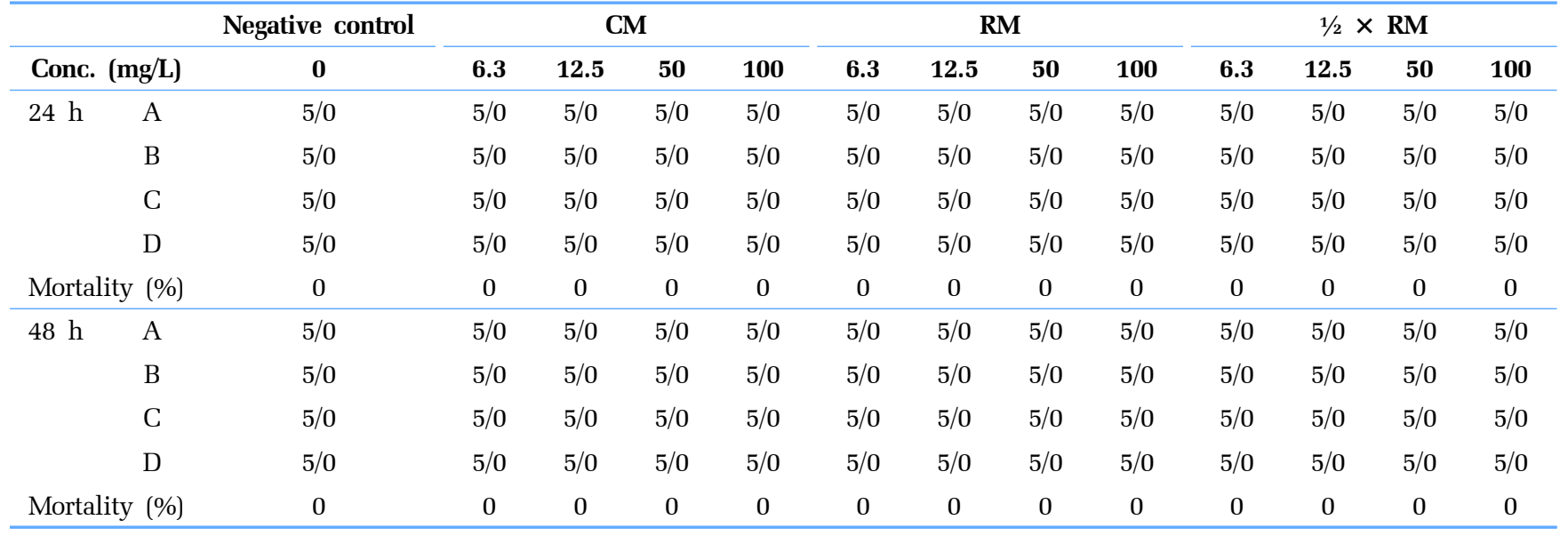

A, B, C, D are four different experimental groups of CM, RM, and $1 / 2 \times$ RM.; a/d indicates number of alive (a) and dead (d) daphnids in each group.

on daphnids compared to the CM. The results also suggest that it is possible to produce biomass with little or no toxicity by using the nutrients recovered from WW following an appropriate regeneration process.

\section{Conclusions}

Granular alumina adsorbent was synthesized to recover nitrate and phosphate from original WW. The recovered nutrients can support the production of satisfactory amounts of cyanobacteria without the problem of toxic and unfavorable substances in the original WW. Another benefit of using RW is that growth under nutrient limitation can be easily implemented to enhance carbohydrate or lipid productivity, without using additional water or complex cultivation processes. Although further research is needed to improve the efficiency of nutrient extraction from WW, the nutrients in RW were better assimilated by Spirulina platensis than commercial chemicals, possibly owing to the absence of counter ions.

\section{Acknowledgments}

This study was supported by the Korea Institute of Toxicology (Grant KK-1805).

\section{References}

1. Abdullah MA, Ahmad A, Shah SMU, et al. Integrated algal engineering for bioenergy generation, effluent remediation, and production of high-value bioactive compounds. Biotechnol. Bioproc. Eng. 2016;21:236-249.

2. Ruiz-Marin A, Mendoza-Espinosa LG, Stephenson T. Growth and nutrient removal in free and immobilized green algae in batch and semi-continuous cultures treating real wastewater. Bioresour. Technol. 2010;101:58-64.

3. Lau PS, Tam NFY, Wong YS. Wastewater nutrients removal by Chlorella vulgaris: Optimization through acclimation. Environ. Technol. 1996;17:183-189.

4. Chen Y, Sun LP, Liu ZH, Martin G, Sun Z. Integration of waste valorization for sustainable production of chemicals and materials via algal cultivation. Top. Curr. Chem. 2017;375:1-38.

5. Xu J, Lo SL, Gong R, Xu Sun X. Control of agricultural non-point source pollution in Fuxian lake with riparian wetlands. Desalin. Water Treat. 2016;57:28570-28580.

6. Xiong JQ, Kurade MB, Jeon BH. Can microalgae remove pharmaceutical contaminants from water? Trends Biotechnol. 2018;36:30-44.

7. Ryu BG, Kim EJ, Kim HS, Kim J, Choi YE, Yang JW. Simultaneous treatment of municipal wastewater and biodiesel production by cultivation of Chlorella vulgaris with indigenous wastewater Bacteria. Biotechnol. Bioproc. Eng. 2014;19:201-210.

8. Ryu BG, Kim J, Yoo G, et al. Microalgae-mediated simultaneous treatment of toxic thiocyanate and production of biodiesel. Bioresour. Technol. 2014;158:166-173.

9. Markou G, Depraetere O, Vandamme D, Muylaert K. Cultivation of Chlorella vulgaris and Arthrospira platensis with recovered phosphorus from wastewater by means of zeolite sorption. Int. J. Mol. Sci. 2015;16:4250-4264.

10. Markou G, Vandamme D, Muylaert K. Using natural zeolite for ammonia sorption from wastewater and as nitrogen releaser for the cultivation of Arthrospira platensis. Bioresour. Technol. 2014;155:373-378.

11. Islam A, Taufiq-Yap YH, Chu CM, Chan ES, Ravindra P. Synthesis and characterization of millimetric gamma alumina spherical particles by oil drop granulation method. J. Porous Mater. 2012;19:807-817.

12. Kim J, Hwang MJ, Lee SJ, et al. Efficient recovery of nitrate and phosphate from wastewater by an amine-grafted adsorbent for cyanobacterial biomass production. Bioresour. Technol. 
2016;205:269-273.

13. Cai T, Park SY, Li Y. Nutrient recovery from wastewater streams by microalgae: Status and prospects. Renew. Sust. Energ. Rev. 2013;19:360-369.

14. Organisation for economic co-operation and development (OECD). Guideline for testing of chemicals, Daphnia sp. acute immobilisation test (Guideline No. 202), Paris, France: OECD; 2004. p. 1-12.

15. Kebede E, Ahlgren G. Optimum growth conditions and light utilization efficiency of Spirulina platensis (= Arthrospira fusiformis) (Cyanophyta) from lake Chitu, Ethiopia. Hydrobiologia 1996;332:99-109.

16. DuBois M, Gilles KA, Hamilton JK, Rebers PA, Smith F. Colorimetric method for determination of sugars and related substances. Anal. Chem. 1956;28:350-356.

17. Lourenço SO, Barbarino E, Lavín PL, Marquez UML, Aidar E. Distribution of intracellular nitrogen in marine microalgae: Calculation of new nitrogen-to-protein conversion factors. Eur. J. Phycol. 2004;39:17-32.

18. Izard J, Limberger RJ. Rapid screening method for quantitation of bacterial cell lipids from whole cells. J. Microbiol. Meth. 2003;55:411-418.

19. Banerjee S, Dubey S, Gautam RK, Chattopadhyaya MC, Sharma YC. Adsorption characteristics of alumina nanoparticles for the removal of hazardous dye, Orange $\mathrm{G}$ from aqueous solutions. Arab. J. Chem. 2017.
20. Beuckels A, Smolders E, Muylaert K. Nitrogen availability influences phosphorus removal in microalgae-based wastewater treatment. Water Res. 2015;77:98-106.

21. Hong SJ, Park YS, Han MA, et al. Enhanced production of fatty acids in three strains of microalgae using a combination of nitrogen starvation and chemical inhibitors of carbohydrate synthesis. Biotechnol. Bioproc. Eng. 2017;22:60-67.

22. Chisti Y. Biodiesel from microalgae. Biotechnol. Adv. 2007;25: 294-306.

23. Amin NF, Khalafallah MA, Ali MA, Abou-Sdera SA, Matter IA. Effect of some nitrogen sources on growth and lipid of microalgae Chlorella sp. for biodiesel production. J. Appl. Sci. Res. 2013;9:4845-4855.

24. Ferreira AL, Loureiro S, Soares AM. Toxicity prediction of binary combinations of cadmium, carbendazim and low dissolved oxygen on Daphnia magna. Aquat. Toxicol. 2008;89:28-39.

25. Nebeker AV, Dominguez SE, Chapman GA, Onjukka ST, Stevens DG. Effects of low dissolved oxygen on survival, growth and reproduction of Daphnia, Hyalella and Gammarus. Environ. Toxicol. Chem. 1992;11:373-379.

26. Borgeraas J, Hessen DO. UV-B induced mortality and antioxidant enzyme activities in Daphnia magna at different oxygen concentrations and temperatures. J. Plankton Res. 2000;22:1167-1183.

27. Kobayashi M, Hoshi T. Analysis of respiratory role of hemoglobin in Daphnia magna. Zool. Sci. 1984;1:523-532. 